\title{
Correction to: Effects of acid type extraction on characterization and sensory profile of duck feet gelatin: towards finding bovine gelatin alternative
}

\author{
Nik Aisyah Nik Muhammad ${ }^{1}$ Nurul Huda ${ }^{2}$ A. A. Karim ${ }^{3}$. \\ Abdorreza Mohammadi Nafchi ${ }^{4}$
}

Published online: 25 October 2017

(C) Springer Science+Business Media, LLC 2017

\section{Correction to: Food Measure}

\section{DOI 10.1007/s11694-017-9661-8}

The original version of this article unfortunately contained a mistake. The first author name was incorrectly submitted and published as Nik Aisyah, N.M. instead of Nik Muhammad, $\mathrm{N}$.

The original article has been corrected.

The online version of the original article can be found under doi:10.1007/s11694-017-9661-8.

Nurul Huda

nhuda1355@gmail.com; nhuda@unisza.edu.my

1 Fish and Meat Processing Laboratory, Food Technology Division, School of Industrial Technology, Universiti Sains Malaysia, 11800 Minden, Penang, Malaysia

2 Food Technology Program, School of Bioresources and Food Industry, Universiti Sultan Zainal Abidin, Gong Badak, 21300 Kuala Terengganu, Terengganu, Malaysia

3 Food Technology Division, School of Industrial Technology, Universiti Sains Malaysia, 11800 Minden, Penang, Malaysia

4 Food Science and Technology Division, Department of Agriculture, Damghan Branch, Islamic Azad University, Damghan, Iran 